\title{
Association of Blastocystis ST6 with higher protease activity among symptomatic subjects
}

Seyed Ahmad Karamati ${ }^{1,2}$, Hamed Mirjalali ${ }^{*}$, Maryam Niyyati ${ }^{* *}$, Abbas Yadegar ${ }^{3}$, Hamid Asadzadeh Aghdaei ${ }^{4}$, Ali Haghighi ${ }^{1}$ and Seyyed Javad Seyyed Tabaei ${ }^{1}$

\begin{abstract}
Background: Blastocystis sp. is an anaerobic intestinal protozoan parasite of humans and a wide range of animals worldwide. In the current study the correlation between the cysteine protease activity of clinical samples of Blastocystis sp. ST1-3 and 6 with the levels of pro-inflammatory cytokines was evaluated.
\end{abstract}

Methods: Stool samples were collected from subjects with or without clinical symptoms. All samples were cultivated in DMEM medium. The bacteria were eliminated or reduced in Blastocystis sp. positive samples subtypes 1-3 and 6 by a variety of antibiotics and consecutive sub-cultures. To prepare parasite lysate, $1 \times 10^{5}$ Blastocystis $\mathrm{sp}$. from each isolate were harvested and lysed using freeze-thaw. Protease activity of each isolate was measured and the gene expression of pro-inflammatory biomarkers in HT-29 cell line sensed by isolates was investigated using quantitative Real-time PCR.

Results: Protease activity assay showed inter- and intra-subtype variations among subtypes regarding the presence of symptoms, while the protease activity of symptomatic isolates was higher than asymptomatic isolates. The highest and lowest levels of protease activity were seen in ST6 and ST2, respectively. However, patterns of the expression of pro-inflammatory biomarkers in HT-29 cell line was different regarding the presence of symptoms and time points. There was no significant correlation between protease activity of different subtypes with the expression levels of proinflammatory biomarkers.

Conclusions: Our study indicated a higher protease activity among isolates from symptomatic compared to asymptomatic subjects, suggesting functional role for proteases in clinical symptoms due to Blastocystis sp. The lack of correlation between the levels of expression of pro-inflammatory biomarkers with subtypes regarding the presence of clinical symptoms proposes the importance of host-related factors in presentation of clinical symptoms.

Keywords: Blastocystis sp., Subtypes, Clinical symptoms, Protease activity, Pro-inflammatory biomarker

*Correspondence: hamed_mirjalali@hotmail.com; maryamniyati@yahoo.com ${ }^{1}$ Department of Medical Parasitology and Mycology, Faculty of Medicine, Shahid Beheshti University of Medical Sciences, Tehran, Iran

${ }^{3}$ Foodborne and Waterborne Diseases Research Center, Research Institute for Gastroenterology and Liver Diseases, Shahid Beheshti University of Medical Sciences, Tehran, Iran

Full list of author information is available at the end of the article

\section{Background}

Blastocystis sp. is a common anaerobic unicellular protozoan parasite isolated from the gastrointestinal tract of humans and a wide range of animals worldwide [1-3]. The high incidence of this parasite has been reported in tropical, subtropical, and developing countries [1, 2, 4].

Blastocystis sp. was described almost a century ago; nevertheless, this organism has remained a controversial protist, which its pathogenic mechanisms are still unclear [5]. Blastocystis sp. was firstly considered as a commensal 
organism, but studies in last decades linked the presence of this protozoan with some intestinal and extra-intestinal clinical manifestations [6-10]. However, the pathogenicity, virulence factors, and other risk factors, which may impact the clinical manifestations related to Blastocystis sp., need to be understood.

Although a little is known about the cellular mechanisms of pathogenesis of Blastocystis sp., it was demonstrated that inflammation of the intestinal mucosa is an expected result of Blastocystis sp. colonization [11, 12]. It was also shown that Blastocystis sp. recruits the inflammatory cells in mice colon [13], and manipulates the immune responses and cytokine release in the colonic epithelial cells [14]. Proteases (particularly cysteine protease) seem to play an important role during the pathogenesis of Blastocystis sp. [15-18]. Proteases released by some pathogens have been reported to have an ability to induce pro-inflammatory cytokines from host cells [19]. This enzyme complex destroys the human secretory immunoglobulin A (sIgA) and helps the parasite to survive and colonize the large intestine [20]. However, interand intra- subtype variations have been linked to the virulence and protease activity of Blastocystis sp., which probably reflect the variations throughout the proteases genes among subtypes [21]. In the current study, for the first time protease activity of human-prevalent Blastocystis sp. subtypes $1-3$, and 6 isolated from symptomatic and asymptomatic subjects was evaluated. As well, the inter-and intra-subtype variations of Blastocystis sp. on the pro-inflammatory cytokines were investigated.

\section{Methods}

\section{Ethical approval}

All procedures performed in this study were in accordance with the ethical standards (IR.SBMU.RIGLD. REC.1395.83) released by the Ethical Review Committee of the Research Institute for Gastroenterology and Liver Diseases, Shahid Beheshti University of Medical Sciences, Tehran, Iran. As well, the study was approved by the ethics committee/institutional review board of the Research Institute for Gastroenterology and Liver Diseases, Shahid Beheshti University of Medical Sciences, Tehran, Iran.

Written informed consents were obtained from all subjects and in the case that participants were under the of 16 years, informed consent was obtained from their parents.

\section{Blastocystis isolates}

The current study was performed on stool samples were collected from apparently healthy subjects and patients with gastrointestinal disorders without known microbial/ non-microbial reasons, from our previous study [22], who referred to the parasitology laboratory located at the Foodborne and Waterborne Diseases Research Center, the Research Institute for Gastroenterology and Liver Diseases, Shahid Beheshti University of Medical Sciences, Tehran, Iran.

\section{Blastocystis cultivation}

All stool samples were microscopically investigated for Blastocystis sp. and other intestinal parasites. In order to cultivate Blastocystis sp., stool samples were cultured in Dulbecco's Modified Eagle Medium (DMEM) (Gibco, Thermo Fisher Scientific, MA, USA) containing penicillin-streptomycin (Sigma, USA), (1000-unit penicillin and $4 \mathrm{mg} / \mathrm{mL}$ streptomycin) supplemented with $10 \%$ heat-inactivated fetal bovine serum (FBS, Sigma-Aldrich, USA), and were incubated in an anaerobic condition at $37^{\circ} \mathrm{C}$. The positive samples were sub-cultured every 3-4 days. Samples without any growth for Blastocystis sp. after 10 days considered as negative.

\section{DNA extraction and subtyping}

Genomic DNA of culture-positive Blastocystis sp. was extracted using total DNA extraction kit (Yekta Tajhiz Azma, Tehran, Iran) and stored at $-20^{\circ} \mathrm{C}$ until PCR amplification. The RD5 (5'-ATCTGGTTGATCCTG CCAGT-3') and BhRDr (5'-GAGCTTTTTAACTGC AACAACG-3') primers were used for molecular subtyping of Blastocystis sp. as mentioned elsewhere [23]. PCR products have been loaded on $1.5 \%$ agarose gel and then sequenced using an ABI 3130 sequencer. The obtained sequences were edited by Chromas software and the subtype determination of isolates were done using Basic Local Alignment Search Tool (BLAST; http://blast.ncbi. nlm.nih.gov/) [22].

\section{Blastocystis subtype purification}

Purification of Blastocystis sp. subtypes and elimination or reducing the number of bacteria were done by a combination of partial purification of parasite by Ficoll gradient (Ficoll-Paque ${ }^{\mathrm{TM}}$ PREMIUM) and inoculation of parasites into fresh medium containing active antibiotics. In this study, approximately 40 Blastocystis sp. isolates from our previous study [22], subtypes ST1-3, ST6 and ST7 were included that during the serial cultivation ST7 was missed. To identify the antibiotic susceptibility of bacteria in each isolate, $50 \mu \mathrm{L}$ of culture medium of each isolate was cultivated onto blood agar, followed by disk diffusion assay. Accordingly, based on the antibiotic susceptibility test, a cocktail of antibiotics, specific to each isolate, was used to reduce the number of bacteria. After a six-month consecutive cultivation by specific antibiotics (a mix of antibiotics consisted of $4000 \mathrm{mg} /$ $\mathrm{ml}$ of ampicillin, $1000 \mathrm{mg} / \mathrm{ml}$ of streptomycin, and 
1000 units of penicillin together with amphotericin B $(50 \mathrm{mg} / \mathrm{ml})$ to eliminate yeasts or filamentous fungi) for each isolate, culture medium was centrifuged in $250 \times \mathrm{g}$ at $25^{\circ} \mathrm{C}$ for $5 \mathrm{~min}$, supernatant containing bacteria was removed and the remained pellet containing purified Blastocystis sp. was washed three times with sterile PBS $(\mathrm{pH}=7.5-8)[24]$.

\section{Preparation of parasite lysates}

Purified parasites without bacteria or with reduced number of bacteria were cultivated in DMEM medium supplemented with $10 \%$ heat inactivated FBS, $1000 \mathrm{mg} / \mathrm{mL}$ of streptomycin, and 1000 units of penicillin, and then incubated at $37^{\circ} \mathrm{C}$ in an Anaerojar (Oxoid, United Kingdom). Two to three-day-old parasites at $\log$ phase were washed three times in PBS at $300 \times g$ for $5 \mathrm{~min}$ at $4{ }^{\circ} \mathrm{C}$. The parasites were counted with Neubauer's improved cell counting chamber (perci color HBG; Germany), and the parasite concentration was adjusted to $1 \times 10^{5}$ parasites/ $\mathrm{mL}$. Finally, parasite lysates were prepared using three freeze-thaw cycles in liquid nitrogen and a $37^{\circ} \mathrm{C}$ water bath, respectively. In order to remove probable remained bacteria, prepared lysate was filtered using polyethersulfone (PES) filters with $0.22 \mu \mathrm{m}$ pore size.

\section{Measurement of the protease activity of the Blastocystis sp. subtypes}

The protease activity of the Blastocystis sp. subtypes in both symptomatic and asymptomatic groups were determined using protease activity assay kit (Abcam, United Kingdom). In brief, $100 \mu \mathrm{L}$ of parasite lysates was added to $300 \mu \mathrm{L}$ of the assay buffer and was centrifuged at $400 \mathrm{~g}$ for $5 \mathrm{~min}$ to remove insoluble materials. Then, $50 \mu \mathrm{L}$ of the supernatant was added to wells of a 96-well plate (black plate with clear bottoms, SPL). For positive control, $5 \mu \mathrm{L}$ of the reconstituted positive control solution was transferred into wells, and the final volume was adjusted to $50 \mu \mathrm{L}$ with assay buffer. A reagent background control containing only $50 \mu \mathrm{L}$ of assay buffer was also prepared. In order to prepare standard curve, volumes of $0,2,4,6,8$, and $10 \mu \mathrm{L}$ of FITC standard were added into a series of standard wells, respectively. To generate $0,0.05$, $0.1,0.150 .2$, and $0.25 \mathrm{nmol} /$ well of the FITC standard, the final volumes were adjusted to $100 \mu \mathrm{L}$ /well with assay buffer, respectively. The reaction mix containing $2 \mu \mathrm{L}$ of protease substrate solution plus $48 \mu \mathrm{L}$ of assay buffer for each well was prepared and added to the wells, except standard wells. Finally, the excitation (ex) and emission (em) of fluorescence of the unquenched FITC generated by proteolytic digestion of the substrates were read at $\mathrm{Ex} /$ $\mathrm{Em}=485 / 530 \mathrm{~nm}$. The fluorescence of the unquenched FITC generated by proteolytic digestion of the substrate measured by $\triangle \mathrm{RFU}=\mathrm{R} 2-\mathrm{R} 1$ formula.

\section{Cell culture}

The human colon adenocarcinoma cell line (HT-29; ATCC HTB-38), which was kindly provided by the Institute Pasteur of Iran, was cultivated in a $25-\mathrm{cm}^{2}$ culture flask (Cell culture Flask, SPL, Korea) containing $5 \mathrm{~mL}$ of high-glucose DMEM medium (DMEM High Glucose, Biosera) supplemented with $5 \%(\mathrm{v} / \mathrm{v})$ heatinactivated FBS, $2 \mathrm{mML}$-glutamine, penicillin (100 U/ $\mathrm{ml}$, Sigma-Aldrich, USA), and streptomycin $(100 \mathrm{mg} /$ $\mathrm{ml}$, Sigma, USA) and incubated in $5 \% \mathrm{CO}_{2}$ and $100 \%$ humidity at $37^{\circ} \mathrm{C}$. Subsequently, after $70-80 \%$ confluency, the cultured flask was washed three times with sterile PBS $(\mathrm{pH}=7)$ and trypsinized using $0.25 \%$ trypsin-EDTA (Gibco, USA). Finally, the cell suspension was diluted in 1:1 ratio with a $0.025 \%(\mathrm{w} / \mathrm{v})$ trypan blue solution (Gibco, USA) and cell counting was carried out with Neubauer's improved cell counting chamber.

\section{Co-incubation of Blast-Ag from different subtypes with HT-29 cell line}

For co-incubation of Blast-Ag and HT29 cell line, $1 \times 10^{5}$ HT-29 cells were seeded in each well of a 12-well plates. The plate was incubated in $5 \% \mathrm{CO}_{2}$ at $37^{\circ} \mathrm{C}$ overnight. After $70-80 \%$ confluency, the parasite lysates prepared from $10^{5}$ of Blastocystis sp. subtypes were added to each well and incubated for six, 12, and $24 \mathrm{~h}$.

\section{RNA extraction, cDNA synthesis, and quantitative real-time PCR}

Total RNA extraction was performed using Total RNA Purification Mini kit (YTA, Tehran, Iran). After adjusting the RNA concentration, first-strand cDNA synthesis was performed using cDNA synthesis kit (YTA, Tehran, Iran) according to the manufacture's instruction. Relative fold differences of the pro-inflammatory biomarkers expression among treated and untreated cells were determined by qreal-time PCR using Rotor-Gene Q (Qiagen, Germany) in a 20 reaction mixture containing $10 \mu \mathrm{L}$ SYBR Green qPCR master mix 2X (Ampliqon, Denmark), $5 \mu \mathrm{M}$ of each primer (Table 1), and $1 \mu \mathrm{L}$ constructed cDNA as template. The amplification conditions were: initial denaturation $95^{\circ} \mathrm{C}$ for $10 \mathrm{~min}$, followed by denaturation at $95^{\circ} \mathrm{C}$ for $20 \mathrm{~s}$, annealing at $59-61^{\circ} \mathrm{C}$ for $30 \mathrm{~s}$, and extension at $72^{\circ} \mathrm{C}$ for $20 \mathrm{~s}$. Melt curve analysis was done in order to determine the presence of probable non-specific PCR amplification or primer dimer formation. The expression of the pro-inflammatory biomarkers was calculated by the $\Delta \Delta \mathrm{CT}$. The relative quantification (RQ) of the targets genes, relative to the $\beta$-actin mRNA, was calculated using relative expression software tool (REST). 
Table 1 The sequence of specific primers used in this study

\begin{tabular}{|c|c|c|}
\hline Genes & Sequence ( $5^{\prime}$ to $\left.3^{\prime}\right)$ & Ref \\
\hline IFN-y & $\begin{array}{l}\text { TGACCAGAGCATCCAAAAGA } \\
\text { CTCTTCGACCTCGAAACAGC }\end{array}$ & [25] \\
\hline IL-12p35 & $\begin{array}{l}\text { TTCACCACTCCCAAAACCTGC } \\
\text { GAGGCCAGGCAACTCCCATTA }\end{array}$ & [26] \\
\hline IL-8 & $\begin{array}{l}\text { TGGCTCTCTTGGCAGCCTTC } \\
\text { TGCACCCAGTTTTCCTTGGG }\end{array}$ & [27] \\
\hline IL-6 & $\begin{array}{l}\text { CCTTAAAGCTGCGCAGAATG } \\
\text { ATTCAATGAGGAGACTTGCC }\end{array}$ & [28] \\
\hline TNF-a & $\begin{array}{l}\text { AGCCCATGTTGTAGCAAACC } \\
\text { TGAGGTACAGGCCCTCTGAT }\end{array}$ & [29] \\
\hline TGF- $\beta$ & $\begin{array}{l}\text { ATGCCCGTATTTATGGAGTT } \\
\text { ATTGTCATTTTGGTCTTGCC }\end{array}$ & [30] \\
\hline$\beta$-actin & $\begin{array}{l}\text { ATGTGGCCGAGGACTTTGATT } \\
\text { AGTGGGGTGGCTTTTAGGATG }\end{array}$ & [31] \\
\hline
\end{tabular}

\section{Statistical analysis}

The statistical analysis of the expression of pro-inflammatory biomarker genes, the protease activities of the subtypes, and the correlation of them with each other and the symptoms were performed in IBM SPSS Statistics for Windows, v22 (Chicago, IL, USA) and GraphPad, Prism (version 8.0.2) software. One-way analysis of variance (ANOVA) followed by Tukey test were used to compare the differences between groups. A correlation or simple linear regression analysis used to determine the correlation between protease activity of the Blastocysis sp. subtypes and the pro-inflammatory biomarkers expression. One-sample t-test incorporated in GraphPad Prism software (version 8.0.2) was employed to calculate mean $\pm \mathrm{SD}$, confidence interval, and statistical correlations. $P$-value 0.05 was considered as statistically significant.

\section{Results}

\section{Blastocystis sp., isolates and axenification}

From almost 40 Blastocystis sp. positive samples, which were included in purification process, only seven isolates subtypes ST1-3 (from both symptomatic and asymptomatic subjects) and ST6 from symptomatic subject remained alive after serial cultures. In addition, the main clinical symptoms related to Blastocystis sp. isolates were gastrointestinal disorders including diarrhea, constipation, nausea, and bloating [22, 24].

\section{Protease activity of Blastocystis subtypes}

The protease activity of Blastocystis sp. isolates from symptomatic isolates was higher than those isolated from asymptomatic subjects. The highest protease activity was seen in ST6 $(0.201 \mathrm{mU} / \mathrm{mL})$. Furthermore, ST2 isolated from asymptomatic subject showed no protease activity. Intra-subtype variations in protease activity revealed that there were no significant differences among Blastocystis sp. subtypes regarding the presence of symptoms except subtype $3(P$-value $=0.014)($ Fig. 1$)$.

\section{The effects of Blastocystis sp. subtypes on the expression} patterns of pro-inflammatory biomarkers in HT-29 cell line In this study the expression patterns of selected proinflammatory biomarkers including IFN- $\gamma$, TNF- $\alpha$, IL-12, IL-8, IL-6, and TGF- $\beta$ were evaluated after exposure to Blast-Ag in three different time points.

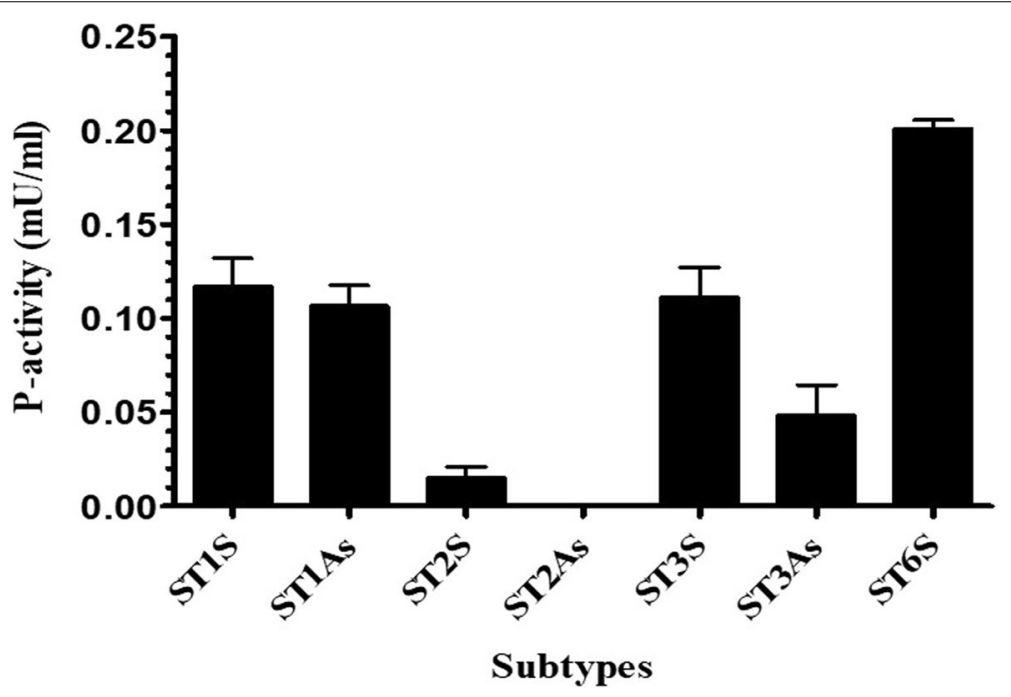

Fig. 1 Protease activity of Blastocystis sp., isolated from symptomatic and asymptomatic subjects. S: symptomatic; As: asymptomatic 


\section{IFN- $\boldsymbol{\gamma}$}

The highest expression level of IFN- $\gamma$ was seen after $24 \mathrm{~h}$ in all isolates with a significant up-regulation in ST2. In addition, intra-subtype variation in the expression of IFN- $\gamma$ regarding the presence of symptoms showed that almost all subtypes isolated from symptomatic patients presented significant overexpression of IFN- $\gamma$ after $24 \mathrm{~h}$. A significant overexpression was also seen in ST1 $(P$-value $=0.013)$ regarding the presence of symptoms, 24h after exposure to Blast-Ag (Fig. 2A, Tables 2 and 3 ).

\section{TNF-a}

There was a downregulation of TNF- $\alpha 6 \mathrm{~h}$ after exposure to Blast-Ag. The highest up-regulation of this gene was observed $12 \mathrm{~h}$ after incubation among all of subtypes, which down-regulated again $24 \mathrm{~h}$ after co-incubation. Apart from ST3, all other subtypes isolated from symptomatic patients have a higher expression compared to isolates from asymptomatic subjects $12 \mathrm{~h}$ after incubation $(P$-value $=0.046)$ (Fig. 2B, Tables 2 and 3).

\section{II-12}

An up-regulation of IL-12 gene in HT-29 cells was observed for almost all isolates $24 \mathrm{~h}$ after exposure to Blast-Ag; however, the highest expression of this gene was observed in $24 \mathrm{~h}$ in all of Blastocystis sp. subtypes excluding ST6S. The highest up-regulation was observed in ST1As (14.45 fold-change). Intra-subtype analysis based on the presence of symptoms revealed that apart from ST3, which IL-12 was significantly upregulated in the isolate from symptomatic patients $12 \mathrm{~h}$ after incubation, an overexpression of IL-12 was observed in asymptomatic subjects $(P$-value $=0.002)$. In addition, the level of IL-12 was significantly upregulated in asymptomatic isolates compared to symptomatic isolates during $24 \mathrm{~h}$ after incubation $(P$-value $=0.000)$ in all samples (Fig. $2 \mathrm{C}$, Tables 2 and 3$)$.

\section{II-8}

Despite of no considerable expression changes compared to the other cytokines, IL- 8 was downregulated in all isolates, particularly in asymptomatic isolates, $24 \mathrm{~h}$ after exposure with Blast-Ag, which was significantly lower than in $6 \mathrm{~h}$ and $12 \mathrm{~h}$ after exposure $(P$-value $=0.003)($ Fig. $2 \mathrm{D}$, Tables 2 and 3$)$.

\section{II-6}

The highest expression of IL-6 was seen in both ST2As and ST2S 24h after exposure to Blast-Ag.
The expression of IL- 6 was significantly increased among symptomatic subjects $24 \mathrm{~h}$ after incubation $(P$-value $=0.027)($ Fig. $2 \mathrm{E}$, Tables 2 and 3$)$.

\section{TGF- $\beta$}

The highest expression of TGF- $\beta$ was seen $12 \mathrm{~h}$ after exposure to Blast-Ag in all isolates. In addition, overexpression of TGF- $\beta$ was observed in ST1 and ST3 isolated from asymptomatic subjects, $12 \mathrm{~h}$ after incubation. An increased downregulated of TGF- $\beta$ was observed in Blastocystis sp. isolates from asymptomatic subjects $6 \mathrm{~h}$ after incubation with Blast-Ag, while it was not statistically significant $(P$-value $=0.31)$ (Fig. 2F, Tables 2 and 3$)$.

\section{Correlation between protease activity and expression of pro-inflammatory cytokines}

Our study indicated that there was no significant correlation between protease activity of and the expression levels of pro-inflammatory cytokines regarding subtypes and the presence of symptoms $(P$-value $=0.078)($ Fig. 3$)$.

\section{Discussion}

The pathogenic role of Blastocystis sp. has remained controversially [32-35] and most of studies failed to link the clinical symptoms and presence of Blastocystis sp.; therefore, this microorganism is considered as a controversial protist [32, 33, 36]. Many hydrolytic enzymes have been identified and suggested to be important pieces in the pathogenicity of Blastocystis sp. [37, 38]. Proteases are considered to play an important role in the pathogenicity of the parasite [35, 39, 40]. Proteases released by Blastocystis sp., such as cysteine and serine proteases, can stimulate apoptosis via caspase 3 [41]. These proteases interrupt the barrier functions, increase the permeability of the epithelial cell lines via regulation of the tight junctions, and disrupt actin filaments [18, 42-44]. The proteases can also cleave sIgA, which leads to escape of the parasite from the host immune system, surviving the protist, and colonizing of the gastrointestinal tract [20, 37].

Abdel-Hameed et al. [40] studied protease activities of Blastocystis sp. ST3 isolated from symptomatic and asymptomatic humans using gelatin sodium dodecyl sulfate polyacrylamide gel electrophoresis (SDS-PAGE) and found the presence of proteases in 17/18 (94.4\%) of symptomatic patients versus $2 / 8(25.0 \%)$ of asymptomatic people, indicating the importance of proteases in pathogenesis of Blastocystis sp. Cysteine proteases secreted by Blastocystis sp. are the most important proteases, which are critical in parasite survival and pathogenicity [33, 35]. Therefore, significant variations in cysteine protease activities among Blastocystis sp. subtypes may lead to differences in their virulence [42]. In our study, 


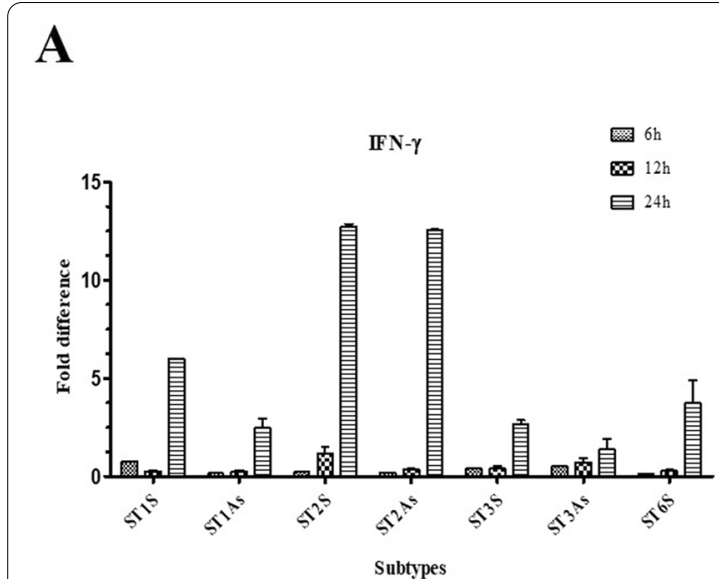

C

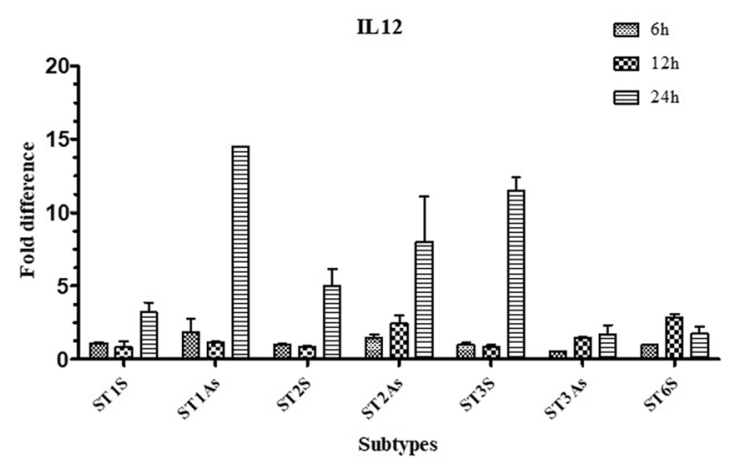

$\mathbf{E}$

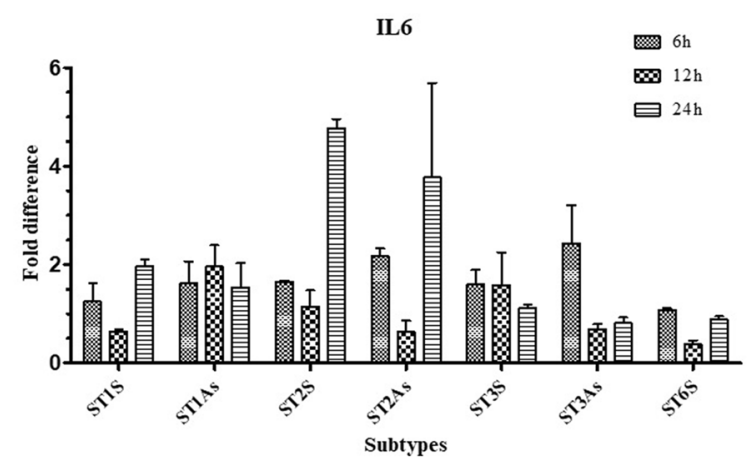

B

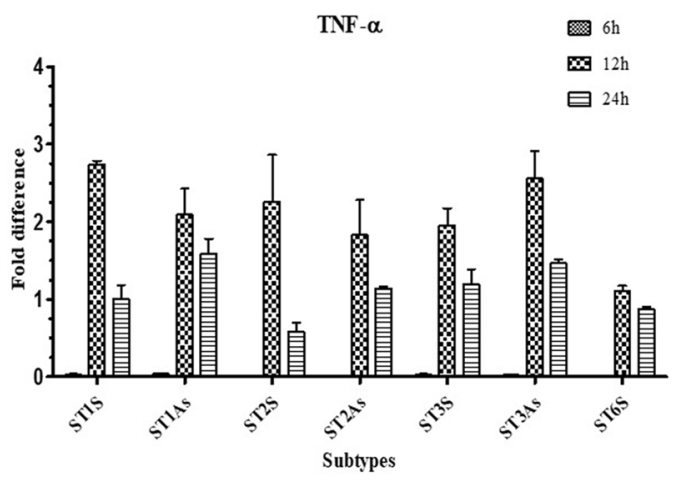

D

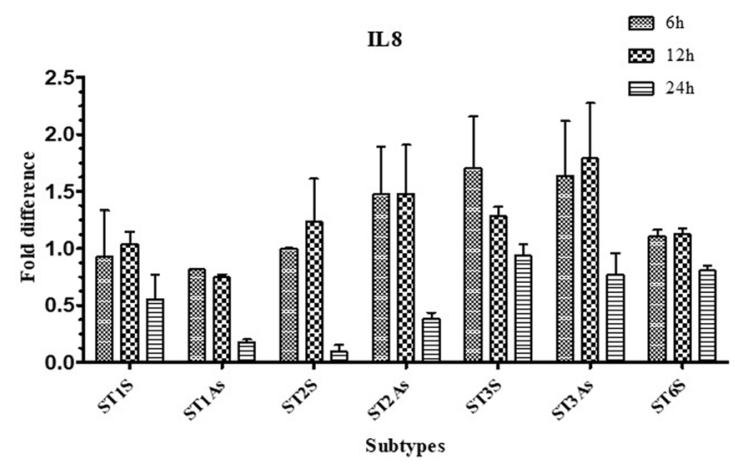

$\mathbf{F}$

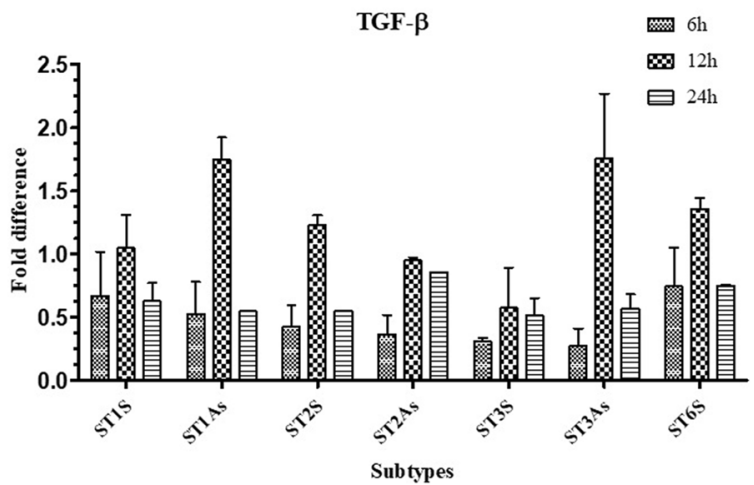

Fig. 2 The expression levels of $\mathbf{A}) \mathrm{IFN}-\gamma, \mathbf{B}) \mathrm{TNF}-\mathrm{a}, \mathbf{C}) \| \mathrm{L}-12, \mathbf{D}) \| \mathrm{L}-8, \mathbf{E}) \mathrm{IL}-6$, and $\mathbf{F}) \mathrm{TGF}-\beta$ in $H \mathrm{~T} 29$ cell line sensing by $B$ last-Ag derived from $1 \times 10^{5}$ Blastocystis sp., ST1-3 and 6 isolated from symptomatic and asymptomatic subjects

higher protease activity was seen among Blastocystis sp. isolated from symptomatic patients compared to those from asymptomatic subjects. This type of differences has been reported from other protists, as well. Reed et al.
[45] demonstrated higher cysteine protease activity of pathogenic strains of Entamoeba histolytica compared to non-pathogenic strains. Mirza et al. [42] studied the variations in cysteine protease activity among Blastocystis 
Table 2 The comparison of the expression levels of pro-inflammatory biomarkers in different time points in symptomatic and asymptomatic isolates

\begin{tabular}{|c|c|c|c|c|c|c|c|c|c|c|}
\hline \multirow[t]{2}{*}{ Cytokines } & \multirow[t]{2}{*}{ Time } & \multicolumn{7}{|c|}{ Expression levels } & \multirow[t]{2}{*}{ Sig. } & \multirow[t]{2}{*}{$P$-value } \\
\hline & & ST1S & ST1As & ST2S & ST2As & ST3S & ST3As & ST6S & & \\
\hline \multirow[t]{3}{*}{ IFN- $\gamma$} & $6 \mathrm{~h}$ & 0.775 & 0.169 & 0.225 & 0.198 & 0.389 & 0.504 & 0.131 & Yes & 0.000 \\
\hline & $12 \mathrm{~h}$ & 0.257 & 0.269 & 1.1585 & 0.3665 & 0.4125 & 0.7325 & 0.2745 & Yes & 0.013 \\
\hline & $24 \mathrm{~h}$ & 6.008 & 2.457 & 12.7415 & 12.57 & 2.684 & 1.37 & 3.7405 & Yes & 0.000 \\
\hline \multirow[t]{3}{*}{ TNF-a } & $6 \mathrm{~h}$ & 0.029 & 0.038 & 0.015 & 0.018 & 0.03 & 0.023 & 0.18 & Yes & 0.000 \\
\hline & $12 \mathrm{~h}$ & 2.732 & 2.0915 & 2.26 & 1.8275 & 1.9535 & 2.5635 & 1.109 & Yes & 0.046 \\
\hline & $24 \mathrm{~h}$ & 1.004 & 1.588 & 0.5785 & 1.139 & 1.189 & 1.4645 & 0.8725 & Yes & 0.009 \\
\hline \multirow[t]{3}{*}{ IL-12 } & $6 \mathrm{~h}$ & 1.102 & 1.852 & 0.956 & 1.43 & 0.9855 & 0.539 & 0.985 & No & 0.351 \\
\hline & $12 \mathrm{~h}$ & 0.825 & 1.118 & 0.8245 & 2.449 & 0.8735 & 1.4885 & 2.8375 & Yes & 0.002 \\
\hline & $24 \mathrm{~h}$ & 3.2 & 14.451 & 5.0375 & 8.035 & 11.4875 & 1.714 & 1.743 & Yes & 0.000 \\
\hline \multirow[t]{3}{*}{ IL-8 } & $6 \mathrm{~h}$ & 0.926 & 0.816 & 0.9975 & 1.4725 & 1.7025 & 1.6335 & 1.104 & No & 0.395 \\
\hline & $12 \mathrm{~h}$ & 1.0375 & 0.747 & 1.232 & 1.4765 & 1.2855 & 1.788 & 1.127 & No & 0.328 \\
\hline & $24 h$ & 0.553 & 0.18 & 0.0945 & 0.385 & 0.9375 & 0.7685 & 0.808 & Yes & 0.003 \\
\hline \multirow[t]{3}{*}{ IL-6 } & $6 \mathrm{~h}$ & 1.247 & 1.6265 & 1.655 & 2.1685 & 1.606 & 2.438 & 1.0805 & No & 0.183 \\
\hline & $12 \mathrm{~h}$ & 0.648 & 1.9585 & 1.153 & 0.6335 & 1.59 & 0.6925 & 0.382 & No & 0.081 \\
\hline & $24 \mathrm{~h}$ & 1.9765 & 1.539 & 4.7745 & 3.7695 & 1.111 & 0.814 & 0.8945 & Yes & 0.027 \\
\hline \multirow[t]{3}{*}{ TGF- $\beta$} & $6 \mathrm{~h}$ & 0.6715 & 0.529 & 0.427 & 0.3665 & 0.3115 & 0.274 & 0.7465 & No & 0.310 \\
\hline & $12 \mathrm{~h}$ & 1.049 & 1.7455 & 1.227 & 0.949 & 0.5745 & 1.7565 & 1.3555 & No & 0.089 \\
\hline & $24 \mathrm{~h}$ & 0.629 & 0.548 & 0.547 & 0.856 & 0.515 & 0.5725 & 0.7515 & Yes & 0.022 \\
\hline
\end{tabular}

sp. isolated from two different hosts, rodent (subtype 4) and avian (subtype 7), and claimed a higher cysteine protease activity among avian isolates. In the line of previous studies, the protease activity of symptomatic isolates of ST1, ST3, and ST6 was significantly higher than that in ST2. Protease activity of the subtype 6 was higher than other Blastocystis sp. subtypes in both symptomatic and asymptomatic subjects. This subtype belongs to birds [46], which may induce a high inflammatory process in non-specific hosts [42].

Proteases released by protozoan parasites have an important role in pathogenesis [47] and seem to stimulate secretion of pro-inflammatory cytokines [48]. Blastocystis sp. proteases are reported to provoke the immune responses [18, 44]. Blastocystis sp. ST1 could arise the pro-inflammatory cytokines including granulocyte-macrophage colony-stimulating factor (GM-CSF) and interleukin 8 (IL-8) [14]. Lim et al. [44] reported that serine proteases released by Blastocystis sp. stimulated the production of pro-inflammatory cytokines in murine macrophage cell line. It was proposed that cysteine proteases secreted from Blastocystis sp. ST4 could induce the IL-8 production from human colonic epithelial cells (HT84) via a nuclear factor $\kappa B(\mathrm{NF}-\kappa B)$-dependent manner [18]. However, a contact-independent cells apoptosis was suggested during the co-incubation of rat intestinal epithelial cells (IEC6) with Blastocystis sp. ST4 [41].
In our study, various expression patterns of IFN- $\gamma$ in HT-29 cell lines were observed among subtypes of Blastocystis sp. during three different point times, and a significant up-regulations of IFN- $\gamma$ was only observed $24 \mathrm{~h}$ after incubation. Iguchi et al. [49] observed a high expression of IFN- $\gamma$ and pro-inflammatory cytokines in the cecal mucosa of rats that were experimentally infected with Blastocystis sp. strain RN94-9. In addition, Chan et al. [50] reported a significant up-regulation of IFN- $\gamma$ cytokine in HCT-116 cell line followed by exposure to Blast-Ag derived from symptomatic patients. These studies support our results that showed higher expression of IFN- $\gamma$ in subtypes 1,3 , and 6 isolated from symptomatic subjects.

Up-regulation of TNF- $\alpha$ gene in HT-29 cell lines by Blastocystis sp. subtypes implied that both Th1 and Th2 responses have important roles in the immunity against Blastocystis sp. These results are in accordance with Chan et al. [50] who suggested activation of the cellular and humoral immune responses against Blastocystis sp. Up-regulation of TNF- $\alpha$ in this study suggested that released proteases by protozoan parasites such as Blastocystis sp. could provoke the activation of $\mathrm{T}$ cells, monocytes/macrophages, and natural killer (NK) cells, which have important roles in the production of pro-inflammatory cytokines such as TNF- $\alpha$, IL- 6 and IL-1, particularly during the acute phase of infection [51-53]. 
Table 3 The comparison of the expression levels of pro-inflammatory biomarkers in Blastocystis sp., isolates regarding different time points

\begin{tabular}{|c|c|c|c|c|c|c|}
\hline \multirow[t]{2}{*}{ Blastocystis isolates } & \multirow[t]{2}{*}{ Cytokines } & \multicolumn{3}{|c|}{ Expression levels } & \multirow[t]{2}{*}{ Sig. } & \multirow[t]{2}{*}{$P$-value } \\
\hline & & $6 \mathrm{~h}$ & $12 \mathrm{~h}$ & $24 \mathrm{~h}$ & & \\
\hline ST1S & IFN- $\nu$ & 0.775 & 0.257 & 6.008 & Yes & 0.000 \\
\hline ST1As & & 0.169 & 0.269 & 2.457 & Yes & 0.018 \\
\hline ST2S & & 0.225 & 1.1585 & 12.7415 & Yes & 0.000 \\
\hline ST2As & & 0.198 & 0.3665 & 12.57 & Yes & 0.000 \\
\hline ST3S & & 0.389 & 0.4125 & 2.684 & Yes & 0.002 \\
\hline ST3As & & 0.504 & 0.7325 & 1.37 & No & 0.317 \\
\hline ST6S & & 0.1315 & 0.2745 & 3.7405 & No & 0.053 \\
\hline ST1S & TNF- $a$ & 0.029 & 2.732 & 1.004 & Yes & 0.001 \\
\hline ST1As & & 0.038 & 2.0915 & 1.588 & Yes & 0.015 \\
\hline ST2S & & 0.015 & 2.26 & 0.5785 & Yes & 0.043 \\
\hline ST2As & & 0.018 & 1.8275 & 1.139 & Yes & 0.036 \\
\hline ST3S & & 0.0305 & 1.9535 & 1.189 & Yes & 0.009 \\
\hline ST3As & & 0.023 & 2.5635 & 1.4645 & Yes & 0.007 \\
\hline ST6S & & 0.0185 & 1.109 & 0.8725 & Yes & 0.001 \\
\hline ST1S & IL-12 & 1.102 & 0.825 & 3.2 & No & 0.054 \\
\hline ST1As & & 1.852 & 1.118 & 14.4515 & Yes & 0.001 \\
\hline ST2S & & 0.956 & 0.8245 & 5.0375 & Yes & 0.034 \\
\hline ST2As & & 1.43 & 2.449 & 8.035 & No & 0.148 \\
\hline ST3S & & 0.9855 & 0.8735 & 11.4875 & Yes & 0.001 \\
\hline ST3As & & 0.539 & 1.4885 & 1.714 & No & 0.183 \\
\hline ST6S & & 0.958 & 2.8375 & 1.743 & No & 0.052 \\
\hline ST1S & IL-8 & 0.926 & 1.0375 & 0.553 & No & 0.509 \\
\hline ST1As & & 0.816 & 0.747 & 0.18 & Yes & 0.000 \\
\hline ST2S & & 0.9975 & 1.232 & 0.0945 & No & 0.069 \\
\hline ST2As & & 1.4725 & 1.4765 & 0.385 & No & 0.176 \\
\hline ST3S & & 1.7025 & 1.2855 & 0.9375 & No & 0.284 \\
\hline ST3As & & 1.6335 & 1.788 & 0.7685 & No & 0.307 \\
\hline ST6S & & 1.104 & 1.127 & 0.808 & Yes & 0.035 \\
\hline ST1S & IL-6 & 1.247 & 0.648 & 1.9765 & No & 0.062 \\
\hline ST1As & & 1.6265 & 1.9585 & 1.539 & No & 0.803 \\
\hline ST2S & & 1.655 & 1.153 & 4.7745 & Yes & 0.002 \\
\hline ST2As & & 2.1685 & 0.6335 & 3.7695 & Yes & 0.000 \\
\hline ST3S & & 1.606 & 1.59 & 1.111 & No & 0.675 \\
\hline ST3As & & 2.438 & 0.6925 & 0.814 & No & 0.121 \\
\hline ST6S & & 1.0805 & 0.382 & 0.8945 & Yes & 0.009 \\
\hline ST1S & TGF- $\beta$ & 0.6715 & 1.049 & 0.629 & No & 0.538 \\
\hline ST1As & & 0.529 & 1.7455 & 0.548 & Yes & 0.026 \\
\hline ST2S & & 0.427 & 1.227 & 0.547 & Yes & 0.025 \\
\hline ST2As & & 0.3665 & 0.949 & 0.856 & Yes & 0.036 \\
\hline ST3S & & 0.3115 & 0.5745 & 0.515 & No & 0.663 \\
\hline ST3As & & 0.274 & 1.7565 & 0.5725 & No & 0.084 \\
\hline ST6S & & 0.7465 & 1.3555 & 0.7515 & No & 0.157 \\
\hline
\end{tabular}

In our study, up-regulation of IL-12 gene was seen in HT-29 cells upon the exposure to Blastocystis sp.; however, the highest expression of this gene was observed after $24 \mathrm{~h}$ incubation. In our study up-regulation of IL-12 gene in HT-29 cell lines in contact with subtype 1 isolated from asymptomatic subjects (ST1As) was significantly 


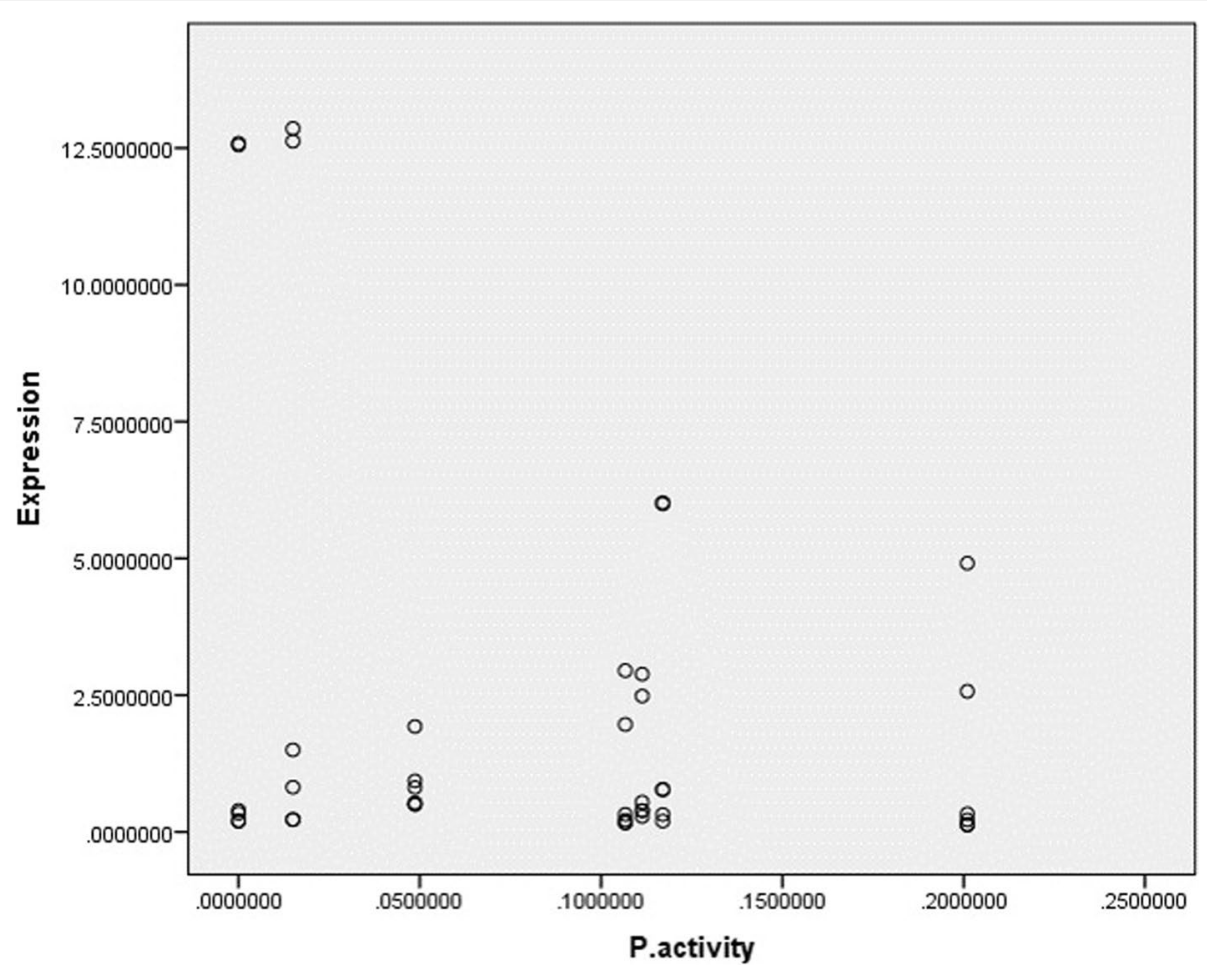

Fig. 3 Statistical analysis showed no correlation between protease activity of Blastocystis sp., isolated from symptomatic and asymptomatic subjects and the expression levels of pro-inflammatory chemokines $(P$-value $=0.078)$

higher than other isolates. The reason for this observation is not clear. Interestingly, the expression patterns of IL-12 gene in HT-29 cell lines in three point times were similar to IFN- $\gamma$. The significant up-regulation of IL-12 and IFN- $\gamma$ were seen in $24 \mathrm{~h}$ after incubation, which implies the important role of the cellular immune system against Blastocystis sp.

Type 1 cytokines such as IL-12 have a critical role in cell-mediated immune responses against variety of pathogens, in particular intracellular pathogens [54]. IFN- $\gamma$ provides a strong stimulation signal for switching the monocytes to activated macrophages, which leads to production and release of IL-12 from macrophages. In contrast, IL-12 stimulates the differentiation of naive T cells into Th1 cells, which encourages the production of inflammatory cytokines such as IFN- $\gamma$ [55]. In response to antigenic stimulation, IL-12 is naturally produced by the immune system cells including macrophage, dendritic cells, neutrophils, and human B-lymphoblastoid cells and plays a crucial role in the generation of Th1 immune responses [54, 56, 57].

As a result, Blastocystis sp., subtypes isolated from both symptomatic and asymptomatic subjects can stimulate the expression of IL-8 gene in HT-29 cell lines. This result is in the line of Lim et al. [44], and implies the potential role of Blastocystis sp. in provoking the inflammatory factors during early stages of infection. Long et al. [14] proposed the ability of Blastocystis sp. in modulation of IL-8 response in intestinal epithelial cells. In addition, Puthia et al. [18] demonstrated that cysteine proteases secreted by $B$. ratti WR1, a zoonotic isolate, can modulate IL- 8 gene expression in human colonic epithelial cells. IL-8 is a CXC chemokine that has an ability in attraction of polymorphonuclear leukocytes into inflammation site, which activates the monocytes and has a role in pathogenesis of inflammatory diseases [58, 59]. However, in the line of previous published study [60] our results suggest that intestinal inflammation induced by Blastocystis sp. is mediated by recruitment of inflammatory cells such as IL-8, particularly at the first phase of infection. The recruitment of IL- 8 into specific site of infection is necessary to trigger the inflammatory processes, which influxes the inflammatory cells into the intestinal mucosa, leading to gastrointestinal disturbances and tissue damage [61].

We observed a diverse patterns of IL- 6 expression in HT-29 cell lines. IL-6has a dual functional role in Th1/ Th2 immune system differentiation [62]. Our results are in accordance with Chan et al. [50] who reported a significant expression of IFN- $\gamma$ and TNF- $\alpha$, IL- 6 , IL-8, and 
TGF- $\beta$ in HCT116 upon the co-incubation with BlastoAg isolated from symptomatic subjects. Lim et al. [44] showed an increased average expression of inflammatory cytokines such as IL-1 $\beta$, IL- 6 , and TNF- $\alpha$ in macrophages in response to Blastocystis sp. ST7. These studies support our results that Blastocystis sp. without considering the subtypes, stimulates the expression levels of IL-6, particularly at $6 \mathrm{~h}$ and $24 \mathrm{~h}$ after co-incubation.

The high expression of TGF- $\beta$ gene were seen during $12 \mathrm{~h}$ after co-incubation compared to other time points in all samples. This result is in accordance with Chan et al. [50] who reported a significant expression of TGF- $\beta$ in HCT116, while the up-regulation of TGF- $\beta$ gene was seen in subtype 1 and subtype 3 isolated from asymptomatic subjects, $12 \mathrm{~h}$ after incubation.

\section{Conclusions}

In the current study, high protease activity of Blastocystis sp. subtypes isolated from symptomatic subjects compared to asymptomatic subjects indicates a potential role for proteases in pathogenesis of Blastocystis sp. In addition, high protease activity of subtypes 6 compared to other subtypes indicates that subtypes that are not human-prevalent and are usually reported from animals may cause more severe symptoms in humans due to their higher protease activity than human-adapted subtypes. As a result, the lack of significant relationship between protease activity of Blastocystis sp. subtypes and the expression levels of proinflammatory biomarkers suggests that either Blastocystis sp.- or host-related factors besides proteases participate in the stimulation of pro-inflammatory biomarkers.

\section{Abbreviations \\ DMEM: Dulbecco's Modified Eagle Medium; FBS: Fetal Bovine Serum; FITC: Fluorescein isothiocyanate; Blast-Ag: Blastocystis antigen; CDNA: comple- mentary DNA; $\beta$-actin: Beta actin; mRNA: messenger RNA; ST: Subtype; IFN: Interferon; IL: Interleukin; TGF: Tumor growth factor.}

\section{Acknowledgements}

This paper has been extracted from the thesis written by Mr. Seyed Ahmad Karamati in School of Medicine, Shahid Beheshti University of Medical Science (Registration No: M341) and was financially supported by the Research Institute for Gastroenterology and Liver Diseases, Shahid Beheshti University of Medical Sciences, Tehran, Iran (grant no. 887). The authors would like to thank all the staffs of the Foodborne and Waterborne Diseases Research Center for their collaboration, especially we would like to thank Mrs. Masoumeh Azimirad for her technical assistance.

\section{Authors' contributions}

Conceived and designed the experiments: HM, MN. Performed the experiments: SAK. Analyzed the data: SAK, HM, AY. Contributed reagents/materials/ analysis/tools/positive samples: HAA, AH, SJST. Wrote the paper: HM, SAK. All authors read and approved the final version of the manuscript.

\section{Funding}

This study was financially supported by the Research Institute for Gastroenterology and Liver Diseases, Shahid Beheshti University of Medical Sciences with grant number: RIGLD-887.

\section{Availability of data and materials}

Generated data including figures and tables were not submitted elsewhere and are included in the article.

\section{Declarations}

Ethics approval and consent to participate

All procedures performed in this study were in accordance with the ethical standards (IR.SBMU.RIGLD.REC.1395.83) released by Ethical Review Committee of the Research Institute for Gastroenterology and Liver Diseases, Shahid Beheshti University of Medical Sciences, Tehran, Iran. As well, the study was approved by the ethics committee/institutional review board of the Research Institute for Gastroenterology and Liver Diseases, Shahid Beheshti University of Medical Sciences, Tehran, Iran.

Written informed consents were obtained from all subjects and in the case that participants were under the of $16 y e a r s$, informed consent was obtained from their parents.

\section{Consent for publication}

Not applicable.

\section{Competing interests}

The authors declare that they have no conflict of interest.

\section{Author details}

${ }^{1}$ Department of Medical Parasitology and Mycology, Faculty of Medicine, Shahid Beheshti University of Medical Sciences, Tehran, Iran. ${ }^{2}$ Department of Medical Parasitology and Mycology, Faculty of Medicine, Tehran Medical Sciences, Islamic Azad University, Tehran, Iran. ${ }^{3}$ Foodborne and Waterborne Diseases Research Center, Research Institute for Gastroenterology and Liver Diseases, Shahid Beheshti University of Medical Sciences, Tehran, Iran. ${ }^{4}$ Basic and Molecular Epidemiology of Gastrointestinal Disorders Research Center, Research Institute for Gastroenterology and Liver Diseases, Shahid Beheshti University of Medical Sciences, Tehran, Iran.

Received: 29 May 2021 Accepted: 6 October 2021

Published online: 19 October 2021

\section{References}

1. Jimenez PA, Jaimes JE, Ramirez JD. A summary of Blastocystis subtypes in north and South America. Parasit Vectors. 2019;12(1):376.

2. Javanmard E, Niyyati M, Ghasemi E, Mirjalali H, Asadzadeh Aghdaei H, Zali MR. Impacts of human development index and climate conditions on prevalence of Blastocystis: a systematic review and meta-analysis. Acta Trop. 2018;185:193-203.

3. Nemati S, Zali MR, Johnson P, Mirjalali H, Karanis P: Molecular prevalence and subtype distribution of Blastocystis sp. in Asia and in Australia. J Water Health. 2021.

4. Deng L, Chai Y, Zhou Z, Liu H, Zhong Z, Hu Y, Fu H, Yue C, Peng G. Epidemiology of Blastocystis sp. infection in China: a systematic review. Parasite (Paris, France). 2019;26:41.

5. Andersen LO, Stensvold CR. Blastocystis in health and disease: are we moving from a clinical to a public health perspective? J Clin Microbiol. 2016;54(3):524-8

6. Casero RD, Mongi F, Sanchez A, Ramirez JD. Blastocystis and urticaria: examination of subtypes and morphotypes in an unusual clinical manifestation. Acta Trop. 2015;148:156-61.

7. Verma R, Delfanian K. Blastocystis hominis associated acute urticaria. Am J Med Sci. 2013:346(1):80-1.

8. Frealle E, El Safadi D, Cian A, Aubry E, Certad G, Osman M, et al. Acute Blastocystis-associated appendicular peritonitis in a child, Casablanca. Morocco Emerg Infect Dis. 2015;21(1):91-4.

9. El Safadi D, Meloni D, Poirier P, Osman M, Cian A, Gaayeb L, et al. Molecular epidemiology of Blastocystis in Lebanon and correlation between subtype 1 and gastrointestinal symptoms. Am J Trop Med Hyg. 2013;88(6):1203-6.

10. Taghipour A, Javanmard E, Mirjalali H, Haghighi A, Tabarsi P, Sohrabi MR, et al. Blastocystis subtype 1 (allele 4); predominant subtype among 
tuberculosis patients in Iran. Comp Immunol Microbiol Infect Dis. 2019;65:201-6.

11. Cekin AH, Cekin Y, Adakan Y, Tasdemir E, Koclar FG, Yolcular BO. Blastocystosis in patients with gastrointestinal symptoms: a case-control study. BMC Gastroenterol. 2012;12(1):122.

12. Zhang H, Li W, Yan Q, He L, Su Y. Impact of Blastocystis hominis infection on ultrastructure of intestinal mucosa in mice. Zhongguo ji sheng chong xue yu ji sheng chong bing za zhi= Chinese J Parasitol Parasitic Dis. 2006;24(3):187-91.

13. Elwakil HS, Hewedi IH. Pathogenic potential of Blastocystis hominis in laboratory mice. Parasitol Res. 2010;107(3):685-9.

14. Long HY, Handschack A, Konig W, Ambrosch A. Blastocystis hominis modulates immune responses and cytokine release in colonic epithelial cells. Parasitol Res. 2001;87(12):1029-30.

15. Noël C, Dufernez F, Gerbod D, Edgcomb VP, Delgado-Viscogliosi P, Ho L-C, et al. Molecular phylogenies of Blastocystis isolates from different hosts: implications for genetic diversity, identification of species, and zoonosis. J Clin Microbiol. 2005;43(1):348-55.

16. Yoshikawa H, Morimoto K, Wu Z, Singh M, Hashimoto T. Problems in speciation in the genus Blastocystis. Trend Parasitol. 2004;20(6):251-5.

17. Sio SW, Puthia MK, Lee AS, Lu J, Tan KS. Protease activity of Blastocystis hominis. Parasitol Res. 2006;99(2):126-30.

18. Puthia MK, Lu J, Tan KS. Blastocystis ratti contains cysteine proteases that mediate interleukin-8 response from human intestinal epithelial cells in an NF-kB-dependent manner. Eukaryot Cell. 2008;7(3):435-43.

19. Siqueira-Neto JL, Debnath A, McCall LI, Bernatchez JA, Ndao M, Reed SL, et al. Cysteine proteases in protozoan parasites. PLoS Negl Trop Dis. 2018;12(8):e0006512.

20. Puthia MK, Vaithilingam A, Lu J, Tan KS. Degradation of human secretory immunoglobulin a by Blastocystis. Parasitol Res. 2005;97(5):386-9.

21. Gonzalez-Arenas NR, Villalobos G, Vargas-Sanchez GB, Avalos-Galarza CA, Marquez-Valdelamar LM, Ramirez-Miranda ME, Olivo-Diaz A, Romero-Valdovinos M, Martinez-Hernandez F, Maravilla P: Is the genetic variability of Cathepsin B important in the pathogenesis of Blastocystis spp.? Parasitol Res 2018; 117(12):3935-43.

22. Rezaei Riabi T, Mirjalali H, Haghighi A, Rostami Nejad M, Pourhoseingholi MA, Poirier P, et al. Genetic diversity analysis of Blastocystis subtypes from both symptomatic and asymptomatic subjects using a barcoding region from the 18S rRNA gene. Infect Genet Evol. 2018;61:119-26.

23. Scicluna SM, Tawari B, Clark CG. DNA barcoding of Blastocystis. Protist. 2006;157(1):77-85.

24. Karamati SA, Mirjalali H, Niyyati M, Rezaei Riabi T, Yadegar A, Asadzadeh Aghdaei $\mathrm{H}$, et al. Comprehensive study of phenotypic and growth rate features of Blastocystis subtypes 1-3 and 6 in symptomatic and asymptomatic subjects. Iran J Parasitol. 2019;14(2):204-13.

25. Munk RB, Sugiyama K, Ghosh P, Sasaki CY, Rezanka L, Banerjee K, et al. Antigen-independent IFN- $\gamma$ production by human naïve CD4 T cells activated by IL-12 plus IL-18. PLoS One. 2011;6(5):e18553.

26. Idelson M, Alper R, Obolensky A, Yachimovich-Cohen N, Rachmilewitz J, Ejzenberg A, et al. Immunological properties of human embryonic stem cell-derived retinal pigment epithelial cells. Stem Cell Rep. 2018;11(3):681-95.

27. Murzyn A, Krasowska A, Augustyniak D, Majkowska-Skrobek G, Łukaszewicz M, Dziadkowiec D. The effect of Saccharomyces boulardii on Candida albicans-infected human intestinal cell lines Caco-2 and Intestin 407. FEMS Microbiol Lett. 2010;310(1):17-23.

28. Liu Y, Zhu XJ, Zeng C, Wu PH, Wang HX, Chen ZC, et al. Microvesicles secreted from human multiple myeloma cells promote angiogenesis. Acta Pharmacol Sinica. 2014;35(2):230-8.

29. Kadekar S, Silins I, Korhonen A, Dreij K, Al-Anati L, Högberg J, et al. Exocrine pancreatic carcinogenesis and autotaxin expression. PLoS One. 2012;7(8):e43209.

30. Saegusa S, Totsuka M, Kaminogawa S, Hosoi T. Cytokine responses of intestinal epithelial-like Caco-2 cells to non-pathogenic and opportunistic pathogenic yeasts in the presence of butyric acid. Biosci Biotechnol Biochem. 2007;71(10):2428-34.

31. Fu J, Bian L, Zhao L, Dong Z, Gao X, Luan H, et al. Identification of genes for normalization of quantitative real-time PCR data in ovarian tissues. Acta Biochim Biophysic Sinica. 2010;42(8):568-74.

32. Tan KS. New insights on classification, identification, and clinical relevance of Blastocystis spp. Clin Microbiol Rev. 2008;21(4):639-65.
33. Tan KS, Mirza H, Teo JD, Wu B, MacAry PA. Current views on the clinical relevance of Blastocystis spp. Curr Infect Dis Rep. 2010;12(1):28-35.

34. Poirier P, Wawrzyniak I, Vivarès CP, Delbac F, El Alaoui H. New insights into Blastocystis spp.: a potential link with irritable bowel syndrome. PLoS Pathog. 2012;8(3):e1002545.

35. Scanlan PD. Blastocystis: past pitfalls and future perspectives. Trend Parasitol. 2012;28(8):327-34.

36. Boorom KF, Smith H, Nimri L, Viscogliosi E, Spanakos G, Parkar U, et al. Oh my aching gut: irritable bowel syndrome, Blastocystis, and asymptomatic infection. Parasite Vectors. 2008; 1 (1):40.

37. Parija SC, Jeremiah S. Blastocystis: taxonomy, biology and virulence. Trop Parasitol. 2013;3(1):17.

38. Nourrisson C, Wawrzyniak I, Cian A, Livrelli V, Viscogliosi E, Delbac F, et al. On Blastocystis secreted cysteine proteases: a legumain-activated cathepsin B increases paracellular permeability of intestinal Caco-2 cell monolayers. Parasitology. 2016;143(13):1713-22.

39. Cian A, El Safadi D, Osman M, Moriniere R, Gantois N, Benamrouz-Vanneste $\mathrm{S}$, et al. Molecular epidemiology of Blastocystis sp. in various animal groups from two French zoos and evaluation of potential zoonotic risk. PloS One. 2017;12(1):e0169659.

40. Abdel-Hameed DM, Hassanin OM. Proteaese activity of Blastocystis hominis subtype3 in symptomatic and asymptomatic patients. Parasitol Res. 2011;109(2):321-7.

41. Puthia MK, Sio SW, Lu J, Tan KS. Blastocystis ratti induces contact-independent apoptosis, F-actin rearrangement, and barrier function disruption in IEC-6 cells. Infect Immun. 2006;74(7):4114-23.

42. Mirza H, Tan KS. Blastocystis exhibits inter- and intra-subtype variation in cysteine protease activity. Parasitol Res. 2009;104(2):355-61.

43. Mirza H, Wu Z, Teo JD, Tan KS. Statin pleiotropy prevents rho kinasemediated intestinal epithelial barrier compromise induced by Blastocystis cysteine proteases. Cell Microbiol. 2012;14(9):1474-84.

44. Lim MX, Png CW, Tay CY, Teo JD, Jiao H, Lehming N, et al. Differential regulation of proinflammatory cytokine expression by mitogen-activated protein kinases in macrophages in response to intestinal parasite infection. Infect Immun. 2014;82(11):4789-801.

45. Reed SL, Keene WE, McKerrow JH. Thiol proteinase expression and pathogenicity of Entamoeba histolytica. J Clin Microbiol. 1989;27(12):2772-7.

46. Ramírez JD, Sánchez LV, Bautista DC, Corredor AF, Flórez AC, Stensvold CR. Blastocystis subtypes detected in humans and animals from Colombia. Infect Genet Evol. 2014;22:223-8.

47. Sajid M, McKerrow JH. Cysteine proteases of parasitic organisms. Mol Biochem Parasitol. 2002;120(1):1-21.

48. Borger P, Koeter G, Timmerman J, Vellenga E, Tomee J, Kauffman $\mathrm{H}$. Proteases from Aspergillus fumigatus induce interleukin (IL)-6 and IL-8 production in airway epithelial cell lines by transcriptional mechanisms. J Infect Dis. 1999;180(4):1267-74.

49. Iguchi A, Yoshikawa H, Yamada M, Kimata I, Arizono N. Expression of interferon gamma and proinflammatory cytokines in the cecal mucosa of rats experimentally infected with Blastocystis sp. strain RN94-9. Parasitol Res. 2009;105(1):135-40.

50. Chan KH, Chandramathi S, Suresh K, Chua KH, Kuppusamy UR. Effects of symptomatic and asymptomatic isolates of Blastocystis hominis on colorectal cancer cell line, HCT116. Parasitol Res. 2012;110(6):2475-80.

51. Becker SM, Cho K-N, Guo X, Fendig K, Oosman MN, Whitehead R, et al. Epithelial cell apoptosis facilitates Entamoeba histolytica infection in the gut. Am J Pathol. 2010;176(3):1316-22.

52. Gurung P, Kanneganti T-D. Immune responses against protozoan parasites: a focus on the emerging role of nod-like receptors. Cell Mol Life Sci. 2016;73(16):3035-51.

53. Vivanco-Cid H, Alpuche-Aranda C, Wong-Baeza I, Rocha-Ramírez L, Rios-Sarabia N, Estrada-Garcia I, et al. Lipopopeptidephosphoglycan from Entamoeba histolytica activates human macrophages and dendritic cells and reaches their late endosomes. Parasit Immunol. 2007:29(9):467-74.

54. Vignali DA, Kuchroo VK. IL-12 family cytokines: immunological playmakers. Nat Immunol. 2012;13(8):722-8.

55. Alspach E, Lussier DM, Schreiber RD. Interferon $y$ and its important roles in promoting and inhibiting spontaneous and therapeutic cancer immunity. Cold Spring Harbor Persp Biol. 2019;11(3):a028480.

56. Zundler S, Neurath MF. Interleukin-12: functional activities and implications for disease. Cyt Grow Fact Rev. 2015;26(5):559-68. 
57. Abbas AK, Lichtman AH, Pillai S. Cellular and molecular immunology: with student consult online access: Elsevier health sciences; 2014.

58. Charo IF, Ransohoff RM. The many roles of chemokines and chemokine receptors in inflammation. New Eng J Med. 2006;354(6):610-21.

59. Cotton JA, Platnich JM, Muruve DA, Jijon HB, Buret AG, Beck PL. Interleukin-8 in gastrointestinal inflammation and malignancy: induction and clinical consequences. Int J Interf Cyto Med Res. 2016;8:13-34.

60. Yakoob J, Abbas Z, Usman MW, Sultana A, Islam M, Awan S, et al. Cytokine changes in colonic mucosa associated with Blastocystis spp. subtypes 1 and 3 in diarrhoea-predominant irritable bowel syndrome. Parasitology. 2014;141(7):957-69.
61. Berkes J, Viswanathan V, Savkovic S, Hecht G. Intestinal epithelial responses to enteric pathogens: effects on the tight junction barrier, ion transport, and inflammation. Gut. 2003;52(3):439-51.

62. Diehl S, Rincón M. The two faces of IL-6 on Th1/Th2 differentiation. Mol Immunol. 2002;39(9):531-6.

\section{Publisher's Note}

Springer Nature remains neutral with regard to jurisdictional claims in published maps and institutional affiliations.
Ready to submit your research? Choose BMC and benefit from:

- fast, convenient online submission

- thorough peer review by experienced researchers in your field

- rapid publication on acceptance

- support for research data, including large and complex data types

- gold Open Access which fosters wider collaboration and increased citations

- maximum visibility for your research: over $100 \mathrm{M}$ website views per year

At BMC, research is always in progress.

Learn more biomedcentral.com/submissions 